\title{
Abnormal Blood Antidiuretic Hormone
}

National Cancer Institute

\section{Source}

National Cancer Institute. Abnormal Blood Antidiuretic Hormone. NCI Thesaurus. Code C78214.

A laboratory test result which indicates abnormal levels of antidiuretic hormone in the blood. 